\title{
Caracterização Morfológica de Ecótipos de ARRoz Daninho (Oryza sativa) Provenientes de Áreas de ARroz IrRIGado ${ }^{1}$
}

\author{
Morphological Characterization of Red Rice (Oryza Sativa) Ecotypes Derived from \\ Irrigated Rice Areas
}

SCHWANKE, A.M.L. ${ }^{2}$, NOLDIN, J. A. ${ }^{3}$, ANDRES, A. ${ }^{4}$, PROCÓPIO, S.O. ${ }^{5}$ e CONCENÇO, G. ${ }^{6}$

RESUMO - Objetivou-se neste estudo a caracterização fenotípica de 16 ecótipos de arroz daninho provenientes de lavouras comerciais dos Estados do Rio Grande do Sul e Santa Catarina, quando comparados aos cultivares BR-IRGA 409, BR-IRGA 410, IRGA 417 e E1 Paso L 144, em casa de vegetação. Foram semeados 16 ecótipos de arroz daninho e os quatro cultivares de arroz irrigado. O cultivo foi realizado em vasos plásticos com capacidade para 9 litros, contendo solo, utilizando-se cinco repetições por genótipo. Foram avaliadas as seguintes variáveis: coloração das folhas, pilosidade, afilhamento efetivo, graus-dia biológico para completar o florescimento, degrane, número de afilhos férteis, área foliar da folha-bandeira, altura de planta, número de sementes por panícula e produção por planta. Os resultados obtidos evidenciam grande variabilidade morfológica entre os ecótipos estudados.

Palavras-chave: arroz-vermelho, crescimento, interferência.

\begin{abstract}
Aspects related to the phenotypical characterization of red rice ecotypes collected in the states of Rio Grande do Sul and Santa Catarina were studied and compared to those of commercial rice cultivars BR-IRGA 409, BR-IRGA 410, IRGA 417, and El Paso L 144. The sixteen red rice ecotypes plus four rice cultivars were sown with five replications in plastic pails filled with 9 liters of soil. The genotypes were described according to the traits proposed by the International Rice Research Institute (IRRI, 1980). The following plant and seed parameters were evaluated: leaf color and hairiness, effective tillering, biological day-degrees to complete the flowering period, seed shattering, number of fertile tillers, flag leaf area, plant height, number of seeds per panicle and seed production. The results showed a great morphological variability among the red rice ecotypes.
\end{abstract}

Keywords: red rice, growth, interference.

\section{INTRODUÇÃO}

A alta infestação das áreas orizícolas com arroz-vermelho tem sido fator limitante ao incremento na produtividade, além de inviabilizar áreas propícias ao cultivo de arroz irrigado. O arroz-vermelho (Oryza sativa), conhecido como arroz daninho, é originário da Ásia e, segundo Noldin et al. (2004), é considerado a mais importante planta infestante da lavoura orizícola do RS, em razão das perdas econômicas causadas à produção de arroz, tanto em rendimento como em qualidade, e da elevação dos custos de produção devido à necessidade de controle e aos problemas operacionais na colheita, secagem e beneficiamento.

O arroz-vermelho é botanicamente classificado como a mesma espécie do arroz comercial, Oryza sativa, com propriedades morfológicas,

1 Recebido para publicação em 21.4.2007 e na forma revisada em 15.1.2008.

2 Mestre em Fitossanidade, FAEM/UFPel, área de concentração Plantas Daninhas, <aschwanke@ricetec.com.br>; ${ }^{3}$ Pesquisador. Ph.D., Epagri/EEI, prof. convidado, Dep. de Fitossanidade, FAEM/UFPel; ${ }^{4}$ Pesquisador da área de Plantas Daninhas da Embrapa Clima Temperado, ${ }^{5}$ Pesquisador da Embrapa Tabuleiros Costeiros, Aracaju, SE; ${ }^{6}$ Mestre em Fisiologia Vegetal, Doutorando do Dep. de Fitotecnia da UFV, bolsista CNPq. 
fisiológicas e bioquímicas similares (Hoagland \& Paul, 1978; Sánchez-Olquín et al., 2007). Sua competitividade e estabelecimento como planta daninha podem ser explicados em função da alta capacidade de produção de matéria seca; da estatura mais elevada de suas plantas para a maioria dos ecótipos predominantes nas lavouras; e do ciclo geralmente mais longo que a maioria dos cultivares utilizados no Estado do Rio Grande do Sul. Entretanto, para o Estado de Santa Catarina, o ciclo do arroz-vermelho é mais curto que o dos cultivares, com elevado degrane e dormência fisiológica das sementes (Noldin, 1995; Silveira et al., 1997).

O crescimento e o desenvolvimento das plantas de arroz-vermelho variam consideravelmente entre ecótipos, em função da capacidade de perfilhamento, do índice de área foliar, da estatura e ciclo dos cultivares de arroz e de ecótipos de arroz-vermelho (Fischer, 1992a; Sánchez-Olquín et al., 2007). Plantas de arroz de porte mais elevado, com crescimento inicial mais rápido, com grande capacidade de perfilhamento e de ciclo médio ou longo, são mais competitivas com o arroz-vermelho do que os cultivares de ciclo curto, porte mais baixo e pouco perfilhadores (Kwon et al., 1991). Por sua vez, ecótipos de arroz-vermelho de porte baixo e com poucos perfilhos são menos competitivos do que os de porte mais alto e com grande capacidade de perfilhamento (Fischer, 1992b). $\mathrm{O}$ arroz-vermelho comumente encontrado certamente não é o mesmo relatado por Dodson (1900), Stubbs (1904) e Constantin (1960) como os primeiros casos de ocorrência de arroz-vermelho nos EUA no ano de 1846. Devido à pressão de seleção, os biótipos de arroz-vermelho encontrados nos dias de hoje tendem a ser semelhantes aos cultivares utilizados atualmente.

Uma ferramenta importante na escolha da forma de manejo mais adequada é o conhecimento do comportamento dos diferentes ecótipos existentes em cada região produtora de arroz, a fim de estabelecer práticas que dificultem a sincronia da floração e impeçam o cruzamento natural do arroz-vermelho com os cultivares de arroz comercial (Silveira et al., 1997).

Craigmiles (1978) afirmou que as características presentes no arroz-vermelho são geneticamente dominantes sobre seus alelos presentes no arroz-branco; com isso, podem ser transferidas por cruzamento, possibilitando assim o surgimento de novos tipos de arrozvermelho.

A diversidade genética entre os ecótipos de arroz-vermelho é bastante variável (Agostinetto et al., 2003; Eberhardt et al., 2003; Noldin et al., 2003a, b, 2006), o que os torna amplamente diferentes, pela presença de vários caracteres morfológicos, fisiológicos e fenológicos. Essas constatações dificultam a recomendação de uma única medida de controle para essa planta daninha; contudo, a união das diferentes práticas de manejo permitiria minimizar os problemas causados pelo arroz daninho.

Objetivou-se com este trabalho identificar e caracterizar diferentes ecótipos de arroz-vermelho presentes nas regiões orizícolas do Rio Grande do Sul e Santa Catarina.

\section{MATERIAL E MÉTODOS}

O experimento foi instalado em casa de vegetação localizada na Estação Experimental de Terras Baixas da Embrapa Clima Temperado (EETB), em Capão do Leão/RS, situada na região físiogeográfica denominada Encosta do Sudeste, com as seguintes constantes geográficas: latitude de $31^{\circ} 52^{\prime} 00^{\prime \prime} \mathrm{W}$, longitude de $52^{\circ} 21^{\prime} 24^{\prime \prime} \mathrm{S}$ e altitude de $13 \mathrm{~m}$.

Os ecótipos de arroz daninho foram coletados em diferentes regiões orizícolas do Rio Grande do Sul (RS) e Santa Catarina (SC), no ano agrícola 2000/2001. As amostras, constituídas de aproximadamente dez panículas, depois de recebidas, foram degranadas manualmente, ajustadas à umidade de $13 \%$ e, em seguida, acondicionadas em sacos de papel devidamente identificados.

Cada amostra recebida foi selecionada visualmente, com o intuito de agrupar, através de características morfológicas, as sementes procedentes de uma determinada região. Esse procedimento foi realizado com base na coloração das glumas, presença ou ausência de aristas, pilosidade e formato das sementes. Cada amostra devidamente uniformizada foi considerada um "ecótipo" e recebeu código de identificação baseado na origem (Tabela 1). 
Tabela 1 - Código de identificação, município de coleta e características das sementes dos ecótipos de arroz daninho e cultivares de arroz avaliados

\begin{tabular}{|c|c|c|c|}
\hline Ecótipo/genótipo & Município de coleta & Cor das glumas & Cor do pericarpo \\
\hline IT & Itajaí-SC & Palha & Vermelha \\
\hline MA & Massaranduba-SC & Palha & Vermelha \\
\hline $\mathrm{CA}$ & Cachoeirinha-RS & Preta & Vermelha \\
\hline SL & São Lourenço do Sul-RS & Palha & Vermelha \\
\hline RG1 & Rio Grande-RS & Palha & Vermelha \\
\hline RG2 & Rio Grande-RS & Palha & Vermelha \\
\hline RG3 & Rio Grande-RS & Palha & Vermelha \\
\hline $\mathrm{TA}$ & Taim-RS & Palha & Vermelha \\
\hline $\mathrm{PE}$ & Pelotas-RS & Dourada & Vermelha \\
\hline $\mathrm{PO}$ & Pedro Osório-RS & Palha & Vermelha \\
\hline $\mathrm{CL}$ & Capão do Leão-RS & Dourada & Vermelha \\
\hline SAP1 & $\mathrm{S}^{\text {to }}$ Antônio da Patrulha-RS & Palha & Vermelha \\
\hline SAP2 & $\mathrm{S}^{\text {to }}$ Antônio da Patrulha-RS & Acinzentada & Vermelha \\
\hline $\mathrm{AG}$ & Arroio Grande-RS & Palha & Vermelha \\
\hline DP & Dom Pedrito-RS & Preta & Vermelha \\
\hline $\mathrm{RS}$ & Rosário do Sul-RS & Palha & Vermelha \\
\hline BR-IRGA 409 & $*$ & Palha & Branca \\
\hline BR-IRGA 410 & $*$ & Palha & Branca \\
\hline IRGA 417 & $*$ & Palha & Branca \\
\hline El Paso L 144 & $*$ & Palha & Branca \\
\hline
\end{tabular}

* Semente básica da Estação Experimental do IRGA, Cachoeirinha-RS.

Após essa etapa de seleção, foram obtidos 16 ecótipos, que foram avaliados em conjunto com quatro cultivares de arroz: BR-IRGA 409, BR-IRGA 410, IRGA 417 e El Paso L 144. Os ecótipos, mais os cultivares, foram descritos e caracterizados de acordo com os descritores morfológicos do International Rice Research Institute (IRRI, 1980).

Foram semeadas 40 sementes de cada um dos materiais (16 ecótipos de arroz daninho e dos quatro cultivares) em bandejas alveoladas de isopor, contendo mistura de substrato agrícola comercial $(50 \%)$ e solo $(50 \%)$. Depois de semeadas, as bandejas foram mantidas em casa de vegetação. A temperatura foi monitorada diariamente, a partir da emergência dos materiais, com a instalação de um termógrafo marca Thies Gottingen. Esses dados foram utilizados no cálculo dos graus-dia necessários para completar o florescimento (Tabela 5).
Quando as plantas atingiram em média três folhas, foram transplantadas para baldes com capacidade para 9 litros, contendo solo. O solo utilizado foi coletado do horizonte A, em área de várzea da Estação Experimental de Terras Baixas da Embrapa, e classificado como Planossolo Pelotas. A adubação química foi feita com a formulação 5-20-20 na dose de $200 \mathrm{~kg} \mathrm{ha}^{-1}$ de NPK, conforme a análise de solo previamente realizada e seguindo as recomendações técnicas da pesquisa para a cultura do arroz irrigado na região Sul do Brasil (SOSBAI, 2005).

À medida que as plantas se desenvolveram, aumentou a lâmina de água nos baldes, e as plantas daninhas foram controladas manualmente. A adubação nitrogenada em cobertura foi feita quando as plantas atingiram o estádio inicial de afilhamento, aplicando-se o equivalente a $20 \mathrm{~kg}$ de nitrogênio por hectare. 
Na etapa seguinte, quando as plantas iniciaram a diferenciação do primórdio (IDP), foram aplicados mais $20 \mathrm{~kg}$ de nitrogênio por hectare.

O delineamento experimental foi de blocos ao acaso com cinco repetições, sendo a unidade experimental constituída de um balde com quatro plantas. Estas plantas foram conduzidas até a colheita.

No período vegetativo foram avaliados a arquitetura, a cor e pilosidade das folhas e o afilhamento efetivo, no momento em que as plantas atingiram o máximo afilhamento. A coloração de folhas foi determinada com base em padrões de referência (placas coloridas) e classificada comparativamente sob luz natural como verde-clara, verde-normal, verde-escura ou verde-azulada. A pilosidade foi determinada no terço médio da folha, pelo tato, sendo classificada em pilosa ou glabra (ausência de pilosidade). O afilhamento efetivo foi obtido pela razão entre o número de afilhos férteis (com panículas) e o número total de afilhos da planta, determinado pela contagem direta em cada planta.

O período de floração foi determinado por meio da tomada das datas de início e fim do florescimento em cada ecótipo estudado. A leitura foi realizada diariamente, e o controle, com contagem diária das panículas emitidas em cada planta. O monitoramento das temperaturas máxima e minima e das datas de início e fim do florescimento possibilitou a determinação dos graus-dia necessários para cada ecótipo completar o florescimento, pela fórmula "(Temp. Máx + Temp. Mín / 2) - Temp. base". Foi adotado o valor de $15^{\circ} \mathrm{C}$ como temperaturabase para arroz irrigado, segundo as recomendações técnicas da pesquisa para a cultura do arroz irrigado na região Sul do Brasil (SOSBAI, 2005).

No período de maturação, previamente à colheita de cada ecótipo, foram avaliados os seguintes parâmetros: degrane, número de afilhos férteis, ângulo do colmo, área foliar da folha-bandeira, altura de planta, número de sementes por panícula e produção por planta (IRRI, 1980). O degrane foi determinado em uma panícula por repetição, quando da maturação do ecótipo. A determinação foi feita através de leve pressão na panícula com a palma da mão e os dedos, sendo a classificação baseada na diferença entre a quantidade de grãos que se desprende e a que fica retida na panícula, sempre pelo mesmo avaliador. Quanto a este item, considerou-se planta madura a que apresentasse visualmente mais de dois terços de suas panículas totalmente dobradas e as sementes resistentes à pressão da unha, momento esse definido como "ponto de colheita". As notas para degrane seguiram a escala de avaliações do International Rice Research Institute (IRRI, 1980), em que o valor 1 representa dificil degrane (pouco ou nenhum grão desprendido), 5 é intermediário ( $25-50 \%$ de grãos removidos) e 9 (mais de $50 \%$ de grãos removidos) é fácil degrane. O ângulo do colmo para determinação do hábito de crescimento (tipo de planta) foi avaliado de acordo com as seguintes classes: ereto $\left(<30^{\circ}\right)$, intermediário $\left(45^{\circ}\right)$, aberto $\left(60^{\circ}\right)$, horizontal $\left(>60^{\circ}\right)$ ou descendente $\left(90^{\circ}\right)$ (IRRI, 1980). O número de afilhos férteis foi determinado pela contagem direta em cada planta do número de colmos com panículas. A altura de planta foi determinada em centímetros, sendo considerada do colo da planta (base do caule) à extremidade da panícula mais alta. A medida da área foliar da folha-bandeira foi realizada quando as panículas já se encontravam totalmente dobradas e as sementes em estádio pastoso. Essa aferição foi realizada com aparelho integrador de área foliar digital marca LICOR (Lambda Instruments Corporation), modelo LI 3050A. Foi aferida a área foliar da folha-bandeira de cada uma das quatro plantas das cinco repetições. O número de sementes por panícula foi determinado em uma panícula por balde - a mesma colhida para avaliação de degrane. A produção por planta de cada ecótipo foi avaliada através do número de afilhos férteis, número de sementes por panícula (média de cinco baldes) e peso de mil sementes (cinco repetições de 100 sementes).

Os dados foram submetidos à análise de variância, e o agrupamento de médias foi realizado pelo teste de Scott-Knott a 5\% de probabilidade. Utilizou-se o programa estatístico Genes (Cruz, 2000), desenvolvido na Universidade Federal de Viçosa-MG.

\section{RESULTADOS E DISCUSSÃO}

Os dados correspondentes à altura de planta encontram-se na Tabela 2. Quanto a 
Tabela 2 - Arquitetura, pilosidade, cor da folha e altura (cm) das plantas dos ecótipos de arroz daninho e cultivares de arroz avaliados no experimento

\begin{tabular}{|c|c|c|c|c|}
\hline Ecótipo/genótipo & Arquitetura de planta & Pilosidade $^{\mathrm{a}}$ & Cor da folha & Altura* $(\mathrm{cm})$ \\
\hline IT & Ereta & $\mathrm{P}$ & Verde-clara & $138,3 \mathrm{e}$ \\
\hline MA & Intermediária & $\mathrm{P}$ & Verde-clara & $144,5 \mathrm{~d}$ \\
\hline CA & Ereta & $\mathrm{P}$ & Verde & $141,3 \mathrm{~d}$ \\
\hline SL & Intermediária & $\mathrm{P}$ & Verde & $155,6 \mathrm{~b}$ \\
\hline RG1 & Ereta & $\mathrm{G}$ & Verde-escura & $171,3 \mathrm{a}$ \\
\hline RG2 & Ereta & $\mathrm{P}$ & Verde-clara & $129,4 \mathrm{~g}$ \\
\hline RG3 & Intermediária & $\mathrm{P}$ & Verde clara & $134,5 \mathrm{e}$ \\
\hline TA & Ereta & $\mathrm{P}$ & Verde & $149,3 \mathrm{c}$ \\
\hline PE & Ereta & $\mathrm{P}$ & Verde & $143,5 \mathrm{~d}$ \\
\hline PO & Intermediária & $\mathrm{P}$ & Verde & $133,4 \mathrm{f}$ \\
\hline CL & Ereta & $\mathrm{P}$ & Verde & $144,9 \mathrm{~d}$ \\
\hline SAP1 & Ereta & $\mathrm{G}$ & Verde-escura & $109,2 \mathrm{~h}$ \\
\hline SAP2 & Intermediária & $\mathrm{P}$ & Verde & $160,3 \mathrm{~b}$ \\
\hline AG & Intermediária & $\mathrm{P}$ & Verde & $160,6 \mathrm{~b}$ \\
\hline DP & Ereta & $\mathrm{P}$ & Verde & $159,8 \mathrm{~b}$ \\
\hline RS & Intermediária & $\mathrm{P}$ & Verde & $143,7 \mathrm{~d}$ \\
\hline BR-IRGA 409 & Ereta & $\mathrm{P}$ & Verde-escura & $94,6 \mathrm{i}$ \\
\hline BR-IRGA 410 & Ereta & $\mathrm{P}$ & Verde-escura & $95,4 \mathrm{i}$ \\
\hline IRGA 417 & Ereta & $\mathrm{G}$ & Verde-escura & $85,2 \mathrm{j}$ \\
\hline E1 Paso L 144 & Ereta & $\mathrm{P}$ & Verde-escura & $92,3 \mathrm{i}$ \\
\hline CV (\%) & - & - & - & 3,15 \\
\hline
\end{tabular}

${ }^{\text {a }} \mathrm{P}=$ com pilosidade.

$\mathrm{G}=$ glabras (ausência de pilosidade)

* Médias seguidas de mesma letra, na mesma coluna, não diferem pelo teste de Scott-Knott a 5\% de significância

essa variável, todos os ecótipos apresentaram altura superior à dos cultivares comerciais. Os valores variaram de 109,2 a $171,3 \mathrm{~cm}$. O ecótipo com menor estatura foi o SAP1, que apresentou estatura de $109,2 \mathrm{~cm}, 15$ a $25 \mathrm{~cm}$ superior à média dos cultivares comerciais.

A diferença de altura entre o arroz daninho e o cultivado continua sendo a característica mais utilizada pelos produtores, como forma de diferenciar os grupos de genótipos, quando da utilização de "rouguing" ou da "barra química" como forma de manejo e controle de áreas infestadas. Como conseqüência dessas práticas, pode ocorrer seleção em favor dos genótipos de menor altura, necessitando-se, conseqüentemente, da utilização de várias práticas ou tecnologias para alcançar controle eficiente dessa invasora. A utilização de "rouguing' ao longo do ciclo - quando possivel, associado ao preparo inicial do solo para eliminar as primeiras camadas de emergência das plantas daninhas - e o uso ocasional da tecnologia Clearfield ${ }^{\circledR}$ parecem ser um pacote quase completo de controle do arroz daninho (Villa et al., 2006). Claro que só a intenção não basta; para isso, o primeiro passo é a correta informação do produtor. Nenhuma tecnologia será capaz de fazer sua parte, se mal aplicada. Esclarecer o produtor sobre a necessidade de adoção de uma série de práticas torna o controle mais eficiente.

Os dados relativos à arquitetura das plantas, bem como cor e pilosidade das folhas, são apresentados na Tabela 2. Entre os ecótipos estudados, sete apresentaram arquitetura de planta intermediária e nove mostraram arquitetura ereta. Plantas com arquitetura de folha 
mais ereta, normalmente, podem ser mais eficientes na captação de luz quando sob altas densidades de plantas, o que poderia favorecer sua permanência ou predominância na população, em relação às de arquitetura menos ereta. Quanto à pilosidade das folhas, somente dois ecótipos apresentaram folhas glabras (não-pilosas), e os demais, folhas pilosas. A pilosidade das folhas poderia influenciar a adesão e taxa efetiva de absorção de herbicidas.

O ecótipo RG1 apresentou altura de planta de arroz daninho típica $(171,3 \mathrm{~cm})$, porém com grãos longos (Tabela 1). Como visto na Tabela 2 , este ecótipo, desconsiderando a altura de planta, mostrou-se muito similar ao cultivar IRGA 417. Já o ecótipo MA apresentou porte intermediário $(144,5 \mathrm{~cm})$, bastante diferente do ecótipo SAP1 (109,2 cm), de menor altura que o arroz daninho tradicional, bem próximo dos cultivares comerciais.

Com relação à coloração das folhas, quatro ecótipos apresentaram coloração verde-clara, dez apresentaram coloração verde, e dois, verde-escura, assim como os cultivares comerciais. Esses resultados justificam a dificuldade verificada por Marques (1983) na realização de "rouguing" em campos de produção de sementes através da utilização dos critérios arquitetura de planta, cor de folhas e pilosidade das folhas.

Características dos ecótipos selvagens foram e vêm sendo passadas às variedades comerciais pelos cruzamentos através dos anos, assim como o inverso também pode ocorrer. Entre as variedades comerciais e ecótipos de arroz daninho (Tabela 2), todas as variedades comerciais apresentaram coloração verdeescura, e somente uma delas, folhas glabras (IRGA 417). Entre os ecótipos de arroz daninho, somente dois apresentaram características de arquitetura de planta, cor e pilosidade semelhantes às do IRGA 417 (RG1 e SAP1), diferindo, no entanto, quanto à altura de planta. Esses dados evidenciam que os ecótipos de arroz selvagem, através de cruzamentos, adquirem certas características das variedades comerciais, enquanto mantêm outras características, como elevada altura, a qual poderia auxiliar na capacidade desta planta de vencer a competição inicial e sombrear as demais plantas próximas a ela.
O genótipo SAP1, por outro lado, apresentou-se semelhante ao cultivar IRGA 417 morfologicamente, apenas diferindo quanto à altura, além de apresentar folhas glabras e cor verde-escura, evidenciando grau mais elevado de hibridação entre este genótipo selvagem e alguma variedade cultivada de folhas glabras.

A presença de três genótipos diferentes em uma mesma localidade (RG1, RG2 e RG3), sendo ereta e glabra, ereta e pilosa e intermediária e pilosa, respectivamente, evidencia que os cruzamentos ocorrem aleatoriamente, desenvolvendo plantas completamente diferentes na mesma área. A possibilidade de se estar analisando outras plantas além de $O$. sativa, ou subespécies, merece atenção especial, sendo essas diferenciações possiveis somente em nivel genético, dado o elevado grau de polimorfismo observado entre as plantas de arroz daninho.

Na presença do genótipo RG1 em lavoura de IRGA 417, certas práticas de controle, como o "rouguing", seriam imprescindiveis a fim de evitar novas hibridações que a tornassem de porte mais baixo, uma vez que este ecótipo já apresenta sementes do tipo longo-fino, é ereto e possui folhas glabras.

De forma geral, observa-se que as plantas de arroz daninho mantêm ainda caracteristicas de coloração mais escura e altura de planta mais elevada que as variedades comerciais (Tabela 2). Um dos fatores que interferem na velocidade com que características de plantas cultivadas aparecem em genótipos selvagens é a pressão de seleção imposta pelo método de controle em uso. Por exemplo, se o sistema de controle utilizado for "rouguing", provavelmente, em uma primeira instância, plantas mais baixas serão selecionadas. Se for a utilização de uma tecnologia de cultivares mutantes, por outro lado, plantas com caracteres genéticos favoráveis serão selecionadas. Se for a adoção de um sistema de cultivo, como o sistema pré-germinado, genótipos de maior dormência podem tomar vantagem por não responderem imediatamente aos estímulos à germinação provocados pelo preparo inicial do solo.

Os períodos do ciclo fenológico foram expressos em dias e divididos em vegetativo, 
reprodutivo e de maturação fisiológica (Tabela 3). Seis ecótipos de arroz daninho, entre os estudados, apresentaram ciclo semelhante ou mais curto que o do cultivar mais precoce (IRGA 417) e quatro se apresentaram mais tardios, com ciclo estatisticamente semelhante ou mais longo que o dos cultivares mais tardios (BR-IRGA 409 e BR-IRGA 410). Os seis ecótipos restantes se comportaram de maneira intermediária dos cultivares, com ciclos que variam de 124 a 127 dias. Segundo Andres \& Machado (2004), o arroz-vermelho possui hábitos similares aos do arroz cultivado, porém seu ciclo costuma ser mais precoce em relação ao cultivar utilizado na lavoura. Sánchez-Olquín et al. (2007) estudaram as características de ecótipos de arroz-vermelho na Costa Rica e as compararam com cultivares comerciais, ressaltando a coincidência de floração como fator agravante na diversidade de ecótipos encontrados.

A grande variabilidade encontrada entre os genótipos quanto ao ciclo total, inclusive em relação às características das sementes, evidencia plantas que se desenvolveram em locais distintos, tanto no interior como fora da lavoura, onde características como o ciclo longo do arroz daninho seriam eliminadas pela colheita da variedade semeada. A periferia da lavoura poderia, portanto, atuar como um banco de genes (através do fluxo gênico), que podem migrar para as novas plantas no interior da lavoura, mantendo características que seriam normalmente eliminadas pelo processo comum de colheita. Isso pode ser observado na Tabela 3 para o genótipo RG1, que apresentou elevada similaridade visual ao cultivar IRGA 417, porém com ciclo mais longo.

O período vegetativo dos genótipos RG1 e SAP1 estende-se em torno de 15 a 20 dias além do ciclo dos cultivares estudados, atrasando conseqüentemente a produção de sementes e facilitando a sua eliminação pelo processo de colheita.

'Os dados correspondentes ao período reprodutivo encontram-se na Tabela 3 . O período reprodutivo dos genótipos apresentou-se bastante similar, com variação máxima de quatro dias. Com relação ao número de dias em que os genótipos permaneceram em florescimento durante o período reprodutivo, dos 16 ecótipos de arroz daninho, 11 completaram a floração em menos de quatro dias, e cinco deles levaram de cinco a sete dias para completar o florescimento, todavia não diferindo estatisticamente.

A ocorrência de um período de floração mais longo, superior a seis dias, favorece, em caso de ocorrência de dias frios, o escape de algumas flores para que ocorra a fecundação e formação de sementes, favorecendo assim a perpetuação do ecótipo. Neste estudo, foi observado que alguns ecótipos concentram sua floração em poucos dias. A taxa de cruzamentos naturais também é função do período em que a planta permanece em floração, conforme exposto por Marques (1983) e Sánchez-Olquín et al. (2007).

O número de afilhos férteis apresentouse bastante variável entre os materiais estudados (Tabela 4), sendo 60\% o menor valor encontrado para os ecótipos de arroz daninho. No entanto, o cultivar BR-IRGA 409 também apresentou afilhamento efetivo baixo, com $55 \%$ de afilhos férteis. O ecótipo TA apresentou 100\% de afilhos férteis e equiparou-se ao melhor dos cultivares comparativos.

Os dados referentes ao número de sementes por panícula evidenciam que alguns ecótipos, como AG, DP e RS, apresentaram número de sementes por panícula muito próximo ao observado para os cultivares comerciais, com exceção do cultivar IRGA 417, que foi superior a todos os demais.

Aproximadamente $68 \%$ dos ecótipos apresentaram massa de mil sementes superior à dos cultivares comparativos. No entanto, com exceção do cultivar BR-IRGA 409, os ecótipos de arroz daninho apresentaram menor produção por planta que os cultivares comerciais, o que é compreensivel, uma vez que os cultivares foram selecionados e melhorados para o fator produtividade, enquanto os ecótipos passam por seleção natural voltada ao aspecto de competição e sobrevivência.

Os resultados encontrados quanto às características morfológicas estão de acordo com Sánchez-Olquín et al. (2007), que afirmam que o arroz-vermelho possui maior índice de acúmulo de massa e perfilhamento e menor produção de grãos. O produto da fotossintese nesses ecótipos é direcionado à produção de 
Tabela 3 - Duração, em dias, do período vegetativo, reprodutivo, maturação e ciclo completo de 16 ecótipos de arroz daninho e quatro cultivares comparativos

\begin{tabular}{|c|c|c|c|c|}
\hline \multirow{2}{*}{ Ecótipo/genótipo } & \multicolumn{4}{|c|}{ Período de desenvolvimento (dias) } \\
\cline { 2 - 5 } & Vegetativo* & Reprodutivo* & Maturação* & Ciclo total* \\
\hline IT & $56 \mathrm{j}$ & $31 \mathrm{a}$ & $29 \mathrm{a}$ & $116 \mathrm{~g}$ \\
\hline MA & $64 \mathrm{f}$ & $28 \mathrm{a}$ & $28 \mathrm{a}$ & $120 \mathrm{e}$ \\
\hline CA & $66 \mathrm{e}$ & $29 \mathrm{a}$ & $30 \mathrm{a}$ & $125 \mathrm{c}$ \\
\hline SL & $71 \mathrm{c}$ & $29 \mathrm{a}$ & $30 \mathrm{a}$ & $130 \mathrm{~b}$ \\
\hline RG1 & $88 \mathrm{a}$ & $28 \mathrm{a}$ & $29 \mathrm{a}$ & $145 \mathrm{a}$ \\
\hline RG2 & $56 \mathrm{j}$ & $32 \mathrm{a}$ & $29 \mathrm{a}$ & $117 \mathrm{~g}$ \\
\hline RG3 & $59 \mathrm{i}$ & $32 \mathrm{a}$ & $27 \mathrm{a}$ & $118 \mathrm{f}$ \\
\hline TA & $68 \mathrm{~d}$ & $30 \mathrm{a}$ & $29 \mathrm{a}$ & $127 \mathrm{c}$ \\
\hline PE & $61 \mathrm{~g}$ & $28 \mathrm{a}$ & $29 \mathrm{a}$ & $118 \mathrm{f}$ \\
\hline PO & $65 \mathrm{e}$ & $31 \mathrm{a}$ & $28 \mathrm{a}$ & $124 \mathrm{c}$ \\
\hline CL & $60 \mathrm{~h}$ & $29 \mathrm{a}$ & $29 \mathrm{a}$ & $118 \mathrm{f}$ \\
\hline SAP1 & $86 \mathrm{a}$ & $28 \mathrm{a}$ & $30 \mathrm{a}$ & $144 \mathrm{a}$ \\
\hline SAP2 & $68 \mathrm{~d}$ & $28 \mathrm{a}$ & $28 \mathrm{a}$ & $124 \mathrm{c}$ \\
\hline AG & $72 \mathrm{c}$ & $28 \mathrm{a}$ & $30 \mathrm{a}$ & $124 \mathrm{c}$ \\
\hline DP & $68 \mathrm{~d}$ & $29 \mathrm{a}$ & $28 \mathrm{a}$ & $125 \mathrm{c}$ \\
\hline RS & $78 \mathrm{~b}$ & $29 \mathrm{a}$ & $28 \mathrm{a}$ & $135 \mathrm{~b}$ \\
\hline BR-IRGA 409 & $75 \mathrm{~b}$ & $30 \mathrm{a}$ & $29 \mathrm{a}$ & $134 \mathrm{~b}$ \\
\hline BR-IRGA 410 & $74 \mathrm{~b}$ & $30 \mathrm{a}$ & $31 \mathrm{a}$ & $135 \mathrm{~b}$ \\
\hline IRGA 417 & $62 \mathrm{f}$ & $29 \mathrm{a}$ & $30 \mathrm{a}$ & $120 \mathrm{e}$ \\
\hline El Paso L 144 & $63 \mathrm{f}$ & $30 \mathrm{a}$ & $28 \mathrm{a}$ & $121 \mathrm{~d}$ \\
\hline CV (\%) & 3,47 & 11,01 & 8,92 & 1,91 \\
\hline
\end{tabular}

* Médias seguidas de mesma letra, na mesma coluna, não diferem pelo teste de Scott-Knott a 5\% de significância.

massa seca de folhas e colmos, de forma que a planta ocupe a área rapidamente e retarde o crescimento de plantas de outros ecótipos ou de outras espécies.

Como pode ser observado na Tabela 5, 69\% dos ecótipos estudados são de fácil degrane, $25 \%$ possuem degrane intermediário e somente $6 \%$ foram classificados como de dificil degrane. Em comparação com os cultivares BR-IRGA 409, BR-IRGA 410 e El Paso L 144, classificados como de degrane intermediário, e IRGA 417, de difícil degrane, é notório que a maioria dos ecótipos de arroz daninho ainda possuem o degrane como forma de dispersão das sementes e perpetuação da espécie. O alto percentual de degrane faz com que a erradicação do arroz daninho se torne uma prática onerosa, o que, segundo Baker et al. (1983), consiste em um dos principais meios de disseminação das sementes de arroz-vermelho, causando reinfestação dos campos em cultivos sucessivos. Por sua vez, sementes de ecótipos que apresentam baixo degrane (uma minoria) acabam sendo eliminadas da lavoura juntamente com grãos da cultura, sendo estes talvez separados posteriormente fora da lavoura. A característica de degrane permite que os grãos caiam ao solo e incrementem o banco de sementes desta invasora na área, característica favorável à sobrevivência do ecótipo.

Para o ecótipo RG1, como já discutido anteriormente para vários atributos, a porcentagem de degrane assemelha-se à da variedade IRGA 417 (indice 1). Com todos os dados avaliados, supõe-se que o ecótipo RG1 possua maior tempo de convivência com o cultivar 
Tabela 4 - Afilhamento efetivo (\%), massa de mil sementes (g), número de sementes por panícula e produção por planta (g) de 16 ecótipos de arroz daninho e quatro cultivares de arroz

\begin{tabular}{|c|c|c|c|c|}
\hline Ecótipo/genótipo & $\begin{array}{c}\text { Afilhamento efetivo } \\
(\%)\end{array}$ & $\begin{array}{l}\text { Massa de mil } \\
\text { sementes }(\mathrm{g})^{\mathrm{a}}\end{array}$ & $\begin{array}{c}\mathrm{N}^{\mathrm{o}} \text { de sementes por } \\
\text { panícula }^{\mathrm{a}}\end{array}$ & $\begin{array}{c}\text { Produção por planta } \\
(\mathrm{g})^{\mathrm{a}}\end{array}$ \\
\hline IT & 66,6 & $33,27 \mathrm{e}$ & $97 \mathrm{e}$ & $12,9 \mathrm{~h}$ \\
\hline MA & 80,0 & $30,52 \mathrm{f}$ & $92 \mathrm{e}$ & $11,2 \mathrm{I}$ \\
\hline $\mathrm{CA}$ & 83,3 & $34,34 \mathrm{~d}$ & $74 \mathrm{~g}$ & $12,7 \mathrm{~h}$ \\
\hline SL & 83,3 & $37,24 \mathrm{~b}$ & $98 \mathrm{e}$ & $18,2 \mathrm{e}$ \\
\hline RG1 & 60,0 & $28,71 \mathrm{~g}$ & $87 \mathrm{f}$ & $7,5 \mathrm{j}$ \\
\hline RG2 & 83,3 & $25,40 \mathrm{k}$ & $103 \mathrm{~d}$ & $13,0 \mathrm{~h}$ \\
\hline RG3 & 71,0 & $25,53 \mathrm{j}$ & $109 \mathrm{~d}$ & $13,9 \mathrm{~g}$ \\
\hline $\mathrm{TA}$ & 100,0 & $35,57 \mathrm{c}$ & $111 \mathrm{~d}$ & $15,8 \mathrm{f}$ \\
\hline PE & 66,0 & $25,61 \mathrm{j}$ & $105 \mathrm{~d}$ & $10,7 \mathrm{I}$ \\
\hline $\mathrm{PO}$ & 80,0 & $24,61 \mathrm{k}$ & $115 \mathrm{~d}$ & $11,3 \mathrm{I}$ \\
\hline $\mathrm{CL}$ & 71,0 & $25,14 \mathrm{k}$ & $102 \mathrm{~d}$ & $12,8 \mathrm{~h}$ \\
\hline SAP1 & 71,0 & $30,59 \mathrm{f}$ & $74 \mathrm{~g}$ & $11,3 \mathrm{I}$ \\
\hline SAP2 & 71,0 & $32,53 \mathrm{e}$ & $82 \mathrm{f}$ & $13,3 \mathrm{~h}$ \\
\hline $\mathrm{AG}$ & 80,0 & $37,69 \mathrm{a}$ & $136 \mathrm{c}$ & $20,5 \mathrm{c}$ \\
\hline DP & 75,0 & $28,27 \mathrm{~h}$ & $142 \mathrm{~b}$ & $24,0 \mathrm{~b}$ \\
\hline RS & 80,0 & $36,57 \mathrm{~b}$ & $134 \mathrm{c}$ & $19,6 \mathrm{~d}$ \\
\hline BR-IRGA 409 & 55,0 & $26,04 j$ & $138 \mathrm{c}$ & $18,2 \mathrm{e}$ \\
\hline BR-IRGA 410 & 85,0 & $27,36 \mathrm{i}$ & $146 \mathrm{~b}$ & $23,9 \mathrm{~b}$ \\
\hline IRGA 417 & 87,0 & $25,15 \mathrm{k}$ & $158 \mathrm{a}$ & $27,8 \mathrm{a}$ \\
\hline El Paso L 144 & 100,0 & $26,53 \mathrm{i}$ & $148 \mathrm{~b}$ & $27,4 \mathrm{a}$ \\
\hline CV $(\%)$ & & 3,65 & 14,64 & 8,19 \\
\hline
\end{tabular}

${ }^{a}$ Médias seguidas da mesma letra, na mesma coluna, não diferem entre si pelo teste de Scott-Knott a 5\% de probabilidade.

IRGA 417 em seu local de coleta do que os demais ecótipos estudados, visto o alto grau de similaridade entre estes (Tabelas 2, 3, 4 e 5).

Nos resultados obtidos para a variável área foliar da folha-bandeira dos ecótipos estudados, todos os ecótipos de arroz daninho apresentaram maior área foliar que a dos cultivares BRIRGA 410, E1 Paso L 144 e IRGA 417. Na comparação com o cultivar BR-IRGA 409, apenas três ecótipos apresentaram maior área foliar que este (Tabela 5). Índices elevados de área foliar podem acarretar maior aproveitamento da luz incidente sobre as plantas, com incremento na conversão de energia solar em energia química (Bressan et al., 2004) e maior crescimento da planta. Contudo, a grande maioria dos ecótipos de arroz-vermelho provavelmente não utiliza a produção de grande volume de sementes como estratégia de propagação, recorrendo a outras alternativas, como degrane, dormência, desenvolvimento mais rápido, etc.

Para graus-dia biológicos, observou-se que os cultivares E1 Paso L 144 e IRGA 417 necessitaram de maior acúmulo de graus-dia para completar o florescimento (Tabela 5). De modo geral, porém, alguns materiais, como SAP1, SAP2 e RG1, completaram o florescimento com metade do número de graus-dia necessário para RG2 e RG3. Conseqüentemente, sugerese que o número de graus-dia necessário para iniciar e finalizar o florescimento é bastante variável entre os ecótipos estudados, estando diretamente relacionado com a duração do ciclo vegetativo (Tabela 3). Ecótipos que necessitaram de menor número de dias para completar o seu ciclo vegetativo também 
Tabela 5 - Área foliar $\left(\mathrm{cm}^{2}\right)$ da folha-bandeira, índice de degrane e graus-dia biológicos necessários para completar o florescimento de 16 ecótipos de arroz daninho e quatro cultivares de arroz

\begin{tabular}{|c|c|c|c|}
\hline Ecótipo/genótipo & ${\text { Área foliar }\left(\mathrm{cm}^{2}\right)^{\mathrm{a}}}^{\mathrm{a}}$ & Índice de degrane $^{\mathrm{b}}$ & Graus-dia $^{\mathrm{a}}$ \\
\hline IT & $55,6 \mathrm{c}$ & 9 & $75,5 \mathrm{a}$ \\
\hline MA & $50,3 \mathrm{c}$ & 9 & $52,8 \mathrm{~d}$ \\
\hline CA & $52,2 \mathrm{c}$ & 5 & $55,0 \mathrm{c}$ \\
\hline SL & $44,2 \mathrm{e}$ & 9 & $55,4 \mathrm{c}$ \\
\hline RG1 & $41,0 \mathrm{f}$ & 1 & $47,9 \mathrm{e}$ \\
\hline RG2 & $66,6 \mathrm{~b}$ & 5 & $99,2 \mathrm{a}$ \\
\hline RG3 & $54,0 \mathrm{c}$ & 9 & $98,4 \mathrm{a}$ \\
\hline TA & $61,5 \mathrm{~b}$ & 9 & $79,1 \mathrm{a}$ \\
\hline PE & $50,1 \mathrm{c}$ & 9 & $75,5 \mathrm{a}$ \\
\hline PO & $72,1 \mathrm{a}$ & 9 & $76,7 \mathrm{a}$ \\
\hline CL & $49,4 \mathrm{c}$ & 5 & $53,5 \mathrm{~d}$ \\
\hline SAP1 & $41,8 \mathrm{f}$ & 5 & $45,7 \mathrm{e}$ \\
\hline SAP2 & $47,1 \mathrm{~d}$ & 9 & $49,6 \mathrm{e}$ \\
\hline AG & $42,2 \mathrm{f}$ & 5 & $55,7 \mathrm{c}$ \\
\hline DP & $48,8 \mathrm{c}$ & 9 & $59,6 \mathrm{~b}$ \\
\hline RS & $42,6 \mathrm{e}$ & 9 & $62,9 \mathrm{~b}$ \\
\hline BR-IRGA 409 & $49,1 \mathrm{c}$ & 5 & $52,5 \mathrm{~d}$ \\
\hline BR-IRGA 410 & $37,1 \mathrm{~g}$ & 5 & $68,2 \mathrm{~b}$ \\
\hline IRGA 417 & $28,6 \mathrm{~h}$ & 1 & $80,6 \mathrm{a}$ \\
\hline El Paso L 144 & $31,1 \mathrm{~h}$ & 5 & $024,2 \mathrm{a}$ \\
\hline CV $\%$ ) & 13,5 & - & 024,5 \\
\hline
\end{tabular}

${ }^{a}$ Médias seguidas da mesma letra, na mesma coluna, não diferem pelo teste de Scott-Knott a 5\% de significância.

${ }^{\mathrm{b}} 1=$ difícil (pouco ou nenhum grão removido); 5 = intermediária $(25-50 \%) ; 9$ = fácil $(>50 \%)$ (IRRI, 1980).

apresentaram, de modo geral, menor necessidade de graus-dia durante o florescimento (Tabela 5). Nos ecótipos RG2 e RG3, esse resultado estendeu-se também ao tempo necessário para completar o ciclo total da planta, mas não como regra geral.

Andres \& Machado (2004) afirmam que os diferentes ecótipos de arroz-vermelho encontrados nas lavouras gaúchas apresentam variabilidade para as características morfológicas e fisiológicas, o que também foi verificado no presente trabalho (Tabelas 2, 3, 4 e 5), mesmo entre ecótipos provenientes da mesma localidade (Tabela 5). Alguns ecótipos possuem os mesmos hábitos do arroz cultivado, confundindo-se com este, e geralmente são mais precoces; dependendo do cultivar utilizado na lavoura, em geral, o seu ciclo biológico é mais curto e o porte mais elevado, sendo eles mais suscetiveis ao acamamento e apresentando maior percentual de degrane.

Do ponto de vista da morfologia das folhas, Hoagland \& Paul (1978) não detectaram diferenças marcantes entre o arroz-vermelho e o arroz cultivado quando avaliados com microscópio eletrônico de varredura, nem mesmo em relação à enzima aryl-acylamidase, responsável pelo metabolismo do herbicida propanil. No entanto, Villa et al. (2006) e Noldin (1995) encontraram diferenças em relação à tolerância a alguns herbicidas.

Dentre os 16 ecótipos de arroz daninho estudados, foi identificado um ecótipo com altura muito similar à dos cultivares utilizados para comparação, o que indica que o "rouguing", muitas vezes, pode ser prejudicial, já que leva a uma 
seleção de plantas principalmente por altura.

Quanto à variável degrane, foi identificado um ecótipo originário do município de Rio Grande, que apresentou forte resistência ao degrane. Este mesmo ecótipo apresentou altura de planta bastante elevada e classe de grão extra-longo, o que também pode indicar avançado nivel de cruzamentos naturais entre o arroz-vermelho e os cultivares.

Deve-se lembrar que os métodos de controle necessitam ser estabelecidos com base nos conhecimentos dos ecótipos existentes na área. Entende-se que o cultivo continuado de uma mesma área, utilizando-se o mesmo método de manejo, selecionará ecótipos de arroz daninho que tenham melhor adaptação àquela situação.

Com base nas informações deste trabalho e na literatura pesquisada, é prudente afirmar que o arroz daninho presente nos campos cultivados da região Sul talvez não seja somente pertencente à espécie Oryza sativa. Trabalhos recentes demonstraram que nos EUA a classificação do arroz-vermelho como $O$. sativa ssp. indica já seria inadequada e que seriam três os distintos tipos de arroz-vermelho. Alguns dos acessos estudados através de técnicas de marcadores moleculares apresentam estreita relação com $O$. sativa ssp. japonica, $O$. nivara e O. rufipogon. As observações morfológicas isoladas não são suficientes para classificação do arroz daninho, pois sua diversidade é muito maior que o previamente assumido. Ademais, essa diversidade deve ser considerada quando do desenvolvimento de técnicas e estratégias de manejo.

Os ecótipos RG2, PO e SAP1 são os que apresentam maior dificuldade de controle através de "rouguing", uma vez que possuem altura de planta similar à dos cultivares comerciais. Os ecótipos de arroz-vermelho presentes em lavouras de arroz irrigado do RS e SC apresentam alta variabilidade fenotípica, sendo a caracterização dos ecótipos predominantes nas áreas de lavoura essencial no planejamento de estratégias de controle. A maioria dos ecótipos de arroz-vermelho avaliados apresenta ciclo vegetativo mais precoce que o dos cultivares comerciais, favorecendo o degrane antes da colheita e o conseqüente aumento no banco de sementes.

\section{LITERATURA CITADA}

AGOSTINETTO, D. et al. Estimativa da perda de rendimento de grãos de arroz irrigado em função da população de plantas e da época da emergência de genótipos de arroz concorrente. In: CONGRESSO BRASILEIRO DE ARROZ IRRIGADO, 3., 2003, Balneário Camboriú. Anais... Itajaí: EPAGRI, 2003. p.435-437.

ANDRES, A.; MACHADO, S. L. O. Plantas daninhas em arroz irrigado. In: GOMES, A. S.; MAGALHÃES JR., A. M. (Eds.). Arroz irrigado no sul do Brasil. Brasília: Embrapa Informação Tecnológica, 2004. p.457-546.

BAKER, J. B.; SONNIER, E. A. Red rice and its control. In: INTERNATIONAL RICE RESEARCH INSTITUTE. Weed control in rice. Los Baños: 1983. p. 327-333.

BRESSAN, R. A.; HASEWAGA, P. M.; LOCY, R. D. Fisiologia do estresse. In: TAIZ, L.; ZEIGER, E. (Eds.). Fisiologia vegetal. Porto Alegre: Artmed, 2004. p. 613-643.

CONSTANTIN, M. J. Characteristics of red rice in Louisiana. 1960. 94 f. (Ph.D. Thesis) - Louisiana State Univiversity, 1960.

CRAIGMILES, J. P. Red rice: research and control. Beaumont. Proceedings... Beaumont, Texas A\&M University, 1978. 56p.

CRUZ, C. D. Software estatístico Genes. Viçosa, MG: Universidade Federal de Viçosa, 2000. CD-ROM.

DODSON, W. R. Rice weeds in Louisiana. Louisiana: 1900. 61 p. (Agric. Esp. Station Bull.).

EBERHARDT, D. S. et al. Manejo de marrecos-de-pequim (Anas sp.) no controle de arroz-vermelho (Oryza sativa). In: CONGRESSO BRASILEIRO DE ARROZ IRRIGADO, 3.; REUNIÃO DA CULTURA DO ARROZ IRRIGADO, 25. 2003, Balneário Camboriú. Anais... Balneário Camboriú: SOSBAI, 2003. p.555-557.

FISHER, A. J. Enfoques para el estudio de la interferencia de las malezas con cultivos. In: CONGRESSO INTERNACIONAL MANEJO INTEGRADO DE PLAGAS, 4., 1992, El Zamorano. Anais... El Zamorano, 1992a. p.310-312

FISHER, A. J. Manejo de malezas: componentes y criterios para su integración. In: CONGRESSO INTERNACIONAL MANEJO INTEGRADO DE PLAGAS, 4., 1992. E1 Zamorano. Anais... El Zamorano: 1992b. p.323-326.

HOAGLAND, R. E.; PAUL, R. N. A comparative SEM study of red rice in several comercial rice (O. sativa) varieties. Weed Sci., v. 26, n. 6, p. 619-625, 1978. 
IRRI; IBPGR. Descriptors for rice Oryza sativa $L$. Los Baños: Laguna, 1980. 21p

KWON, S. L.; SMITH Jr, R. J.; TALBERT, R. E. Red rice (Oryza sativa) control and suppression in rice (O. sativa).

Weed Technol., v. 5, n. 3, p. 811-816, 1991.

MARQUES, L. F. Variabilidade do arroz vermelho e preto (Oryza sativa L) e suas conseqüências na produção de sementes. 1983. $62 \mathrm{f}$. (Mestrado em Tecnologia de Sementes) - Universidade Federal de Pelotas, Pelotas, 1983.

NOLDIN, J. A. Characterization, seed longevity, and herbicide sensitivity of red rice (Oryza sativa $\mathrm{L}$.) ecotypes, and red rice control in soybeans [Glycine max (L.) Merr.]. 1995. 218 f. Thesis (Ph.D in Agronomy). Texas A\&M University, College Station, 1995.

NOLDIN, J. A. et al. Adaptabilidade de populações híbridas F2 de arroz-daninho com arroz transgênico resistente ao herbicida amônio-glufosinate: I - avaliações da etapa vegetativa. In: CONGRESSO BRASILEIRO DE ARROZ IRRIGADO, 3., 2003, Balneário Camboriú. Anais... Itajaí: EPAGRI, 2003a, p. 561-563.

NOLDIN, J. A. et al. Adaptabilidade de populações híbridas F2 de arroz-daninho com arroz transgênico resistente ao herbicida amônio-glufosinate: II - períodos de desenvolvimento e componentes da produtividade. In: CONGRESSO BRASILEIRO DE ARROZ IRRIGADO, 3 , REUNIÃO TÉCNICA DA CULTURA DO ARROZ IRRIGADO, 25., 2003, Balneário Camboriú. Anais... Itajaí: EPAGRI, 2003b. p. 564-566.
NOLDIN, J. A. et al. Desempenho de populações híbridas $\mathrm{F}_{2}$ de arroz-vermelho (Oryza sativa) com arroz trangênico $(O$. sativa ) resistente ao herbicida amônio-glufosinate.

Planta Daninha, v. 22, n. 3, p. 381-395, 2004

NOLDIN, J. A.; CHANDLER, J. M.; MCCAULEY, G. N. Seed longevity of red rice ecotypes buried in soil. Planta Daninha, v. 24, n. 1, p. 611-620, 2006.

SANCHEZ-OLQUIN, E. et al. Vegetative and reproductive development of Costa Rican weedy rice compared with commercial rice (Oryza sativa). Planta Daninha, v. 25, n. 1, p. 13-23, 2007.

SILVEIRA, C. A. et al. Características morfológicas e desenvolvimento fenológico de biótipos de arroz vermelho (Oryza sativa L). In: REUNIÃO DA CULTURA DO ARROZ IRRIGADO, 22., 1997. Balneário Camboriú. Anais... Balneário Camboriú: EPAGRI/SOSBAI, 1997. p. $431-433$

SOSBAI. Arroz irrigado: recomendações técnicas da pesquisa para o Sul do Brasil. Santa Maria: 2005, 123p.

STUBBS, W. C.; DODSON, W. R; BROWN, C. A. Rice Louisiana: 1904. 36 p. (Agric. Exp. Stn. Bull., 77)

VILLA, S. C. C. et al. Red rice control in two rice (Oryza sativa) genotypes tolerant to imidazolinone herbicides. Planta Daninha, v. 24, n. 3, p. 549-555, 2006 